\title{
Research on Smart Grid Risk Assessment Based on Matter- Element Extenics
}

\author{
Jing $\mathrm{Zhou}^{1^{*}}$ and Zhaoxi $\mathrm{Mu}^{2}$ \\ ${ }^{1}$ School of Control and Computer Engineering, North China Electric Power \\ University, Beijing 102206, China \\ ${ }^{1}$ zhoujing108@ncepu.edu.cn, ${ }^{2}$ mzx0521@126.com
}

\begin{abstract}
In order to comprehensively manage risks of smart grid and to make risk assessment more scientific, in this paper a smart grid risk assessment system is established in terms of 5 aspects, i.e., technology risk, management risk, implementation (environment) risk, economy risk and safety risk. Then a matter-element-based risk assessment model is put forward. Finally, with help of this model, the correlation degree of current smart grid risk rank in China is worked out and corresponding risks have been analyzed and assessed
\end{abstract}

Keywords: smart grid; extenics; risk assessment; matter-element model

\section{Introduction}

So far, study on smart grid is still in the beginning stage worldwide. Rare research work about smart grid risk assessment has been done. In comparison with traditional power grid, smart grid is a multi-discipline, multi-industry, comprehensive and large project, which greatly enhances the capacity of accessing new energy. Smart grid involves both renewable energy resources on the power generation side and new electrical equipments on the user side to make the interaction between users more convenient with a challenge to face greater risks. Therefore, risk management of smart grid is getting more important and it is necessary to assess the risk of smart grid in an allround and scientific way. At present, many assessment methods and principles are applicable, such as expert grade method, analytical hierarchy process (AHP), fuzzy analysis and so on. In literature [1], assessment indicator system was established from five aspects, i.e., finance, technology, safety, management and external risks. Then, a model based on multi-hierarchy fuzzy assessment was used to analyze the risk of smart grid in China. In literature [2], focusing on the differences between domestic and overseas assessment system of smart grid, the maturity degree of IBM power grid, the development assessment system proposed by DOE of U.S.A, and the benefits assessment system of EU were compared with the resource-saving and environment-friendly assessment system of smart grid in domestic, and then advice and measures to improve the ability to assess smart grid in China were elicited. In literature [3], a rank correlationgrey triangle cluster method was used to assess risks in smart grid from 5 aspects which were establishment of project, technology, environment, safety and management. In literatures [4-6], research on rating smart grid in terms of the market risk, project risk and operation risk had been conducted actively. Based on the existing achievement of risk assessment in smart grid, a qualitative-quantitative combined method is put forth in this paper, which introduces concepts of correlation function and correlation degree of extendable set in matter-element extenics. Finally, with the help of this method, the risk of smart grid in China has been assessed and rated.

${ }^{*}$ Corresponding Author 


\section{Assessment-related Basic Theories in Matter-element Extenics}

\subsection{Matter-element Theory}

In 1983, Professor CHAI Wen put forth the theory of extenics [7], which mainly researches incompatible objects to turn them into compatible ones by finding out the contradiction mechanism among them [8]. The common idea to analyze and solve this kind of problem is to establish matter-element model by means of various transforms of incompatible objects [9].

As one of basic theories in extenics, matter-element is a formalized description method. Therefore, the matter $\mathrm{N}$, the character $\mathrm{C}$ and its value $\mathrm{V}$ can be described as a triple as $R=(N, C, V)$, where $N, C, V$ are three tuples of matter-element $R$.

When matter $\mathrm{N}$ is with more than one characters, $\mathrm{n}$-dimensional matter-element would be used as below:

$$
R=(N, c, v)=\left[\begin{array}{l}
R_{1} \\
R_{2} \\
\ldots \\
R_{n}
\end{array}\right]=\left[\begin{array}{rrr}
N & c_{1} & v_{1} \\
c_{2} & v_{2} \\
\ldots & \ldots \\
c_{n} & v_{n}
\end{array}\right]
$$

Where $R_{i}=\left(N, c_{i}, v_{i}\right), i=1,2, \ldots, n$ is a sub-element of matter-element $\mathrm{R}$.

\subsection{Extendable Set}

As another one of basic theories in extenics, Extendable Set can not only qualitatively describe characters of a matter but also quantitatively demonstrate the correlation degree of each character of a matter. A positive value of the correlation degree represents that a matter has a character significantly, and a negative value represents that a matter doesn't have a character, and the value " 0 " means that a matter may have or not have a character. Then elements in a same domain can be classified into different hierarchies according this value.

Extendable Set is generally described with correlation function. In extenics, the distance from a point $x$ on real axis to an interval $X_{0}=(a, b)$ is defined as below [10].

$$
\rho\left(x, X_{0}\right)=\left|x-\frac{a+b}{2}\right|-\frac{b-a}{2}
$$

\subsection{Establishment of Matter-element Extenics-based Assessment Model}

\section{(1) Classical Domain and Joint Domain}

Firstly, let $N_{j}$ be the $j$ th risk rank, then character variables $c_{i}(i=1,2, \ldots, n)$ is defined within the range of $v_{j i}$, which is called Classical Domain. Secondly, let $p$ be the rank of combined risk and then character variables $c_{i}(i=1,2, \ldots, n)$ vary within a range called Joint Domain. Besides, let $p_{0}$ be the assessed matter element, then the values of character variables $c_{i}(i=1,2, \ldots, n)$ are the assessed data. Matter-Element matrixes for Classical Domain and for Joint Domain are defined as $R_{j}$ and $R_{p}$ respectively, and Matter-Element to be assessed is denoted as $R_{0}$. The expressions for $R_{j}, R_{p}$ and $R_{0}$. are here below individually. 


$$
\begin{aligned}
& R_{j}=\left(N_{j}, c_{i}, v_{j i}\right)=\left[\begin{array}{ccc}
N_{j} & c_{1} & v_{j 1} \\
& c_{2} & v_{j 2} \\
\ldots & \ldots \\
& c_{n} & v_{j n}
\end{array}\right]=\left[\begin{array}{c}
N_{j} \\
c_{1}\left(\mathrm{a}_{j 1}, \mathrm{~b}_{j 1}\right) \\
c_{2}\left(\mathrm{a}_{j 2}, \mathrm{~b}_{j 2}\right) \\
\ldots(\ldots, \ldots) \\
c_{n}\left(\mathrm{a}_{j n}, \mathrm{~b}_{j n}\right)
\end{array}\right] \\
& R_{p}=\left(p, c_{i}, v_{p i}\right)=\left[\begin{array}{ccc}
p & c_{1} v_{p 1} \\
& c_{2} v_{p 2} \\
\ldots & \ldots \\
& c_{n} v_{p n}
\end{array}\right]=\left[\begin{array}{cc}
p & c_{1}\left(\mathrm{a}_{p 1}, \mathrm{~b}_{p 1}\right) \\
& c_{2}\left(\mathrm{a}_{p 2}, \mathrm{~b}_{p 2}\right) \\
& \ldots(\ldots, \ldots) \\
& c_{n}\left(\mathrm{a}_{p n}, \mathrm{~b}_{p n}\right)
\end{array}\right] \\
& R_{0}=\left[\begin{array}{rrr}
p_{0} & c_{1} & v_{1} \\
c_{2} & v_{2} \\
\cdots & \cdots \\
c_{n} & v_{n}
\end{array}\right]
\end{aligned}
$$

\section{(2) Weight}

Order relation method is applied to calculate the weight of each indicator [11]. The sum of weight makes the formula below true.

$$
\sum_{i=1}^{n} \omega_{i}=1
$$

\section{(3) Establishment and Calculation of Correlation Function}

Correlation Function of each indicator against the risk rank $j$ is defined as:

$$
K_{j}\left(v_{i}\right)= \begin{cases}\frac{-\rho\left(v_{i}, V_{j i}\right)}{\left|V_{j i}\right|} & v_{i} \in V_{j i} \\ \frac{\rho\left(v_{i}, V_{j i}\right)}{\rho\left(v_{j}, V_{p i}\right)-\rho\left(v_{j}, V_{j i}\right)} & v_{i} \notin V_{j i}\end{cases}
$$

Where $\rho\left(v_{i}, V_{j i}\right)$ is the distance from the matter-element value to the Classical Domain of indicator $c_{i}, \rho\left(v_{i}, V_{p i}\right)$ is the distance from the matter-element value to the Joint Domain of indicator $c_{i}$, and $\left|V_{j i}\right|$ is the distance from indicator $c_{i}$ to the Classical Domain of the $j$ th risk rank.

The correlation degree of each rank for the assessed matter-element can be calculated in the formula below.

$$
K_{j}\left(p_{0}\right)=\sum_{i=1}^{n} \omega_{i} K_{j}\left(v_{i}\right)
$$

The followed formula helps to judge if the risk rank of the assessed object is the jth. 
$K_{j}=\max \left\{K_{j}\left(p_{0}\right)\right\} j=1,2, \ldots, \mathrm{m}$

\section{Matter-element Extenics-based Risk Assessment Model of Smart Grid}

\subsection{Construction of Assessment Indicator System}

In this paper, Expert investigation method is applied. According to the achievement of research on risk assessment in smart grid worldwide, the assessment indicator system is built up and shown in Figure 1. The first-level indicator-Smart Grid Risk is subdivided into 5 second-level indicators as Technology Risk, Management Risk, Environment Risk, Economy Risk and Safety Risk. Then, indicators are further subdivided into 18 thirdlevel indicators.

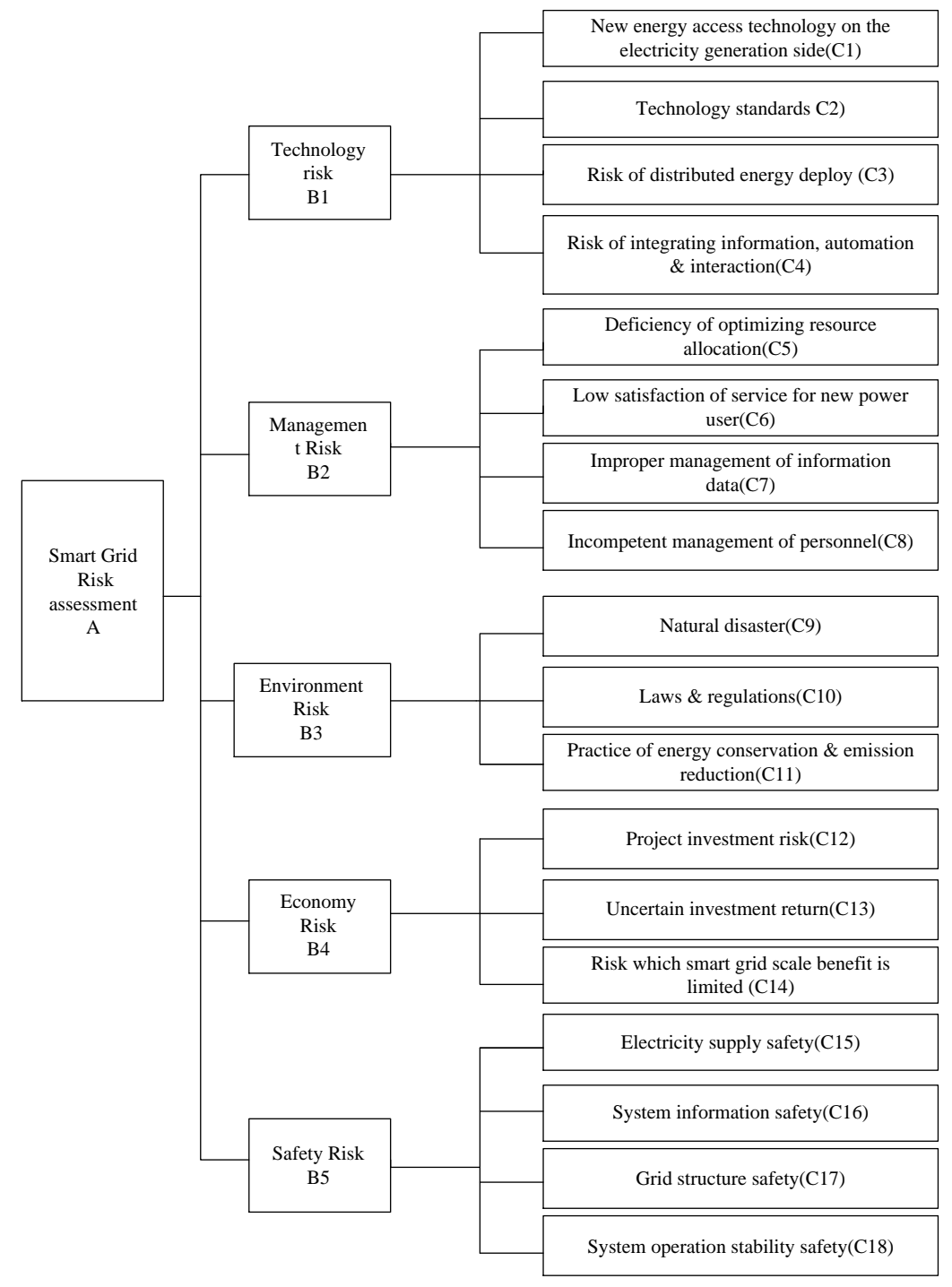

Figure 1. Assessment Indicator System of Smart Grid Risk

\section{(1) Technology Risk}

Technology is a vital factor to develop smart grid so that Technology Risk of smart grid is very high. Technology Risk mainly occurs due to new energy access of the 
electricity generation side, technology standards, distributed energy deploy, and the function integration of information, automation and interaction.

\section{(2) Management Risk}

In Smart Grid, new characters appear on the electricity generation side, the demand side, and due to the structure grid and so on, which is a new challenge in management. Risks mainly include the deficiency of optimizing resource allocation, the low satisfaction of service for new power user, the improper management of information data, and the incompetent management of personnel.

\section{(3) Environment Risk (implementation risk)}

While operating, smart grid will take environment risks resulted from natural disasters, laws \& regulations, and practice of energy conservation \& emission reduction.

\section{(4) Economy Risk}

Smart grid is a vital part of new energy infrastructure. It is characterized with great investment and long investment cycle to result in risk of project investment, risk of uncertain investment return and risk of limited scale benefit in smart grid.

\section{(5) Safety Risk}

Safety risks mainly include electricity supply safety, system information safety, grid structure safety and stability of system operation safety.

\subsection{Weight of Indicator based on Rank Correlation Analysis (RCA)}

RCA is a methodology to determine weight of indicator and improved from AHP (Analytical Hierarchy Process) [12]. It includes three steps. Firstly, indicators are ranked according to their importance. Secondly, the relative importance degree between adjacent indicators is estimated. Thirdly, the subjective weight of each indicator is calculated quantitatively.

Compared with traditional AHP, RCA is characterized with simpler calculation, unlimited number of assessment schemes and more practical value without requirements of either judge matrix or consistency check.

\section{(1) Rank Correlation}

In this paper, the preferential rank correlations of indicators have been ordered by experts as laws $\&$ regulations > technology standards > new energy access technology on the electricity generation side $>$ electricity supply safety $>$ the low satisfaction of service for new power user > system information safety > risk of distributed resource deploy > project investment risk > risk of system operation instability > the deficiency of optimizing resource allocation $>$ the improper management of information data $>$ grid structure safety $>$ practice of energy conservation \& emission reduction $>$ technology risk of integrating information, automation \& interaction > incompetent management of personnel $>$ Natural disasters $>$ risk of uncertain investment return $>$ risk which scale benefit is limited.

\section{(2) The Relative Importance Degree between Adjacent Indicators}

Rational judgment $r_{k}$ is defined as the ratio of the importance degree of indicator $x_{k-1}$ to that of indicator $x_{k}$ as described as in Table 1 . 
Table 1. Assigned Value of $r_{k}$

\begin{tabular}{c|c}
\hline Value & \multicolumn{1}{c}{ Description } \\
\hline .0 & Indicator $x_{k-1}$ is as important as indicator $x_{k}$ \\
.2 & Indicator $x_{k-1}$ is slightly more important than indicator $x_{k}$ \\
.4 & Indicator $x_{k-1}$ is obviously more important than indicator $x_{k}$ \\
.6 & Indicator $x_{k-1}$ is much more important than indicator $x_{k}$ \\
.8 & Indicator $x_{k-1}$ is extremely more important than indicator $x_{k}$ \\
\hline
\end{tabular}

\section{(3) Calculation of Weight Coefficient $\omega_{k}$}

According to the result of judgment on the relative importance degree, weight coefficient $\omega_{k}$ can be calculated with the following formulas.

$$
\begin{aligned}
& \omega_{m}=\left(1+\sum_{k=2}^{m} \prod_{i=k}^{m} r_{i}\right)^{-1} \\
& \omega_{k-1}=r_{k} \omega_{k} \quad(k=2, \ldots, m-1)
\end{aligned}
$$

Then weight coefficients of indicators have been worked out respectively as:

$\omega=(0.164,0.197,0.044,0.008,0.019,0.086,0.015,0.007,0.005,0.197,0.011,0.036,0.003$, $0.002,0.103,0.061,0.015,0.026)$.

\subsection{Calculation of Classical Domain, Joint Domain and the Assessed Matter- Element}

\section{(1) Calculation of Classical Domain}

It is assumed that there is no risk indicator with the value" 0 ". The value for each risk indicator varies within the interval of $(0,10]$. According to the severity, values of risk are divided into 5 intervals of $(0,2),[2,4),[4,6),[6,8),[8,10]$, which denote lower risk, low risk, general risk, high risk and higher risk respectively. The classical domain of higher risk $R_{5}$ is expressed as below.

$$
R_{5}=\left[\begin{array}{rr}
N_{5} & C_{1}[8,10] \\
C_{2} & {[8,10]} \\
\ldots & {[\ldots, \ldots]} \\
C_{17} & {[8,10]} \\
C_{18} & {[8,10]}
\end{array}\right]
$$

Likewise, classical domains for lower risk $R_{1}$, low risk $R_{2}$, general risk $R_{3}$, and high risk $R_{4}$ can be expressed in the similar way.

\section{(2) Calculation of Joint Domain}

The joint domain of risk assessment is denoted as $R_{p}$ which consists of all value ranges of each character to be assessed. $R_{p}$ is expressed as below. 


$$
R_{p}=\left[\begin{array}{ccc}
p & C_{1} & (0,10] \\
& C_{2} & (0,10] \\
& \ldots & (\ldots, \ldots] \\
& C_{17} & (0,10] \\
& C_{18} & (0,10]
\end{array}\right]
$$

\section{(3) Calculation of Matter-element to be Assessed}

By statistically analyzing materials of questionnaire from and discussion with experts, the result is shown in Table 2. The mean value of each risk indicator is taken as the present value of smart grid risk, and then assessed matter-element $R_{0}$ has been worked out.

Table 2. Investigation Result

\begin{tabular}{|c|c|c|c|c|c|c|c|}
\hline Indicator & $\min$ & $\max$ & mean & \begin{tabular}{|l} 
Indicator \\
\end{tabular} & $\min$ & $\max$ & mean \\
\hline $\mathrm{C}_{1}$ & 5 & 7 & 6.9 & $\mathrm{C}_{10}$ & 6 & 8.5 & 7.5 \\
\hline $\mathrm{C}_{2}$ & 6 & 9 & 7.8 & $\mathrm{C}_{11}$ & 5 & 6.5 & 5.6 \\
\hline $\mathrm{C}_{3}$ & 4.5 & 9.3 & 5.8 & $\mathrm{C}_{12}$ & 1 & 2.5 & 2.1 \\
\hline $\mathrm{C}_{4}$ & 2 & 8 & 6.1 & $\mathrm{C}_{13}$ & 3.5 & 5 & 4.5 \\
\hline $\mathrm{C}_{5}$ & 3 & 8 & 4.1 & $\mathrm{C}_{14}$ & 2 & 3 & 2.8 \\
\hline $\mathrm{C}_{6}$ & 7 & 9.6 & 7.7 & $\mathrm{C}_{15}$ & 7 & 8.5 & 7.9 \\
\hline $\mathrm{C}_{7}$ & 5 & 8.5 & 6.4 & $\mathrm{C}_{16}$ & 3 & 6 & 3.4 \\
\hline $\mathrm{C}_{8}$ & 7.5 & 8.8 & 8.2 & $\mathrm{C}_{17}$ & 6.9 & 9.8 & 7.7 \\
\hline $\mathrm{C}_{9}$ & 3 & 4 & 3.2 & $\mathrm{C}_{18}$ & 8 & 9.8 & 8.7 \\
\hline & & & $R_{0}=$ & $\left.\begin{array}{ll}C_{1} & 6.9 \\
C_{2} & 7.8 \\
C_{3} & 5.8 \\
C_{4} & 6.1 \\
C_{5} & 4.1 \\
C_{6} & 7.7 \\
C_{7} & 6.4 \\
C_{8} & 8.2 \\
C_{9} & 3.2 \\
C_{10} & 7.5 \\
C_{11} & 5.6 \\
C_{12} & 2.1 \\
C_{13} & 4.5 \\
C_{14} & 2.8 \\
C_{15} & 7.9 \\
C_{16} & 3.4 \\
C_{17} & 7.7 \\
C_{18} & 8.7\end{array}\right]$ & & & \\
\hline
\end{tabular}




\subsection{Calculation of the Correlation Degree and the Rank of Smart Grid Risk Indicator.}

The correlation degree of risk rank for each indicator has been worked out following formula (2) and formula (7). The result is shown in Table 3. Then the risk rank that each risk indicator belongs to is shown in Table 4 .

Table 3. Correlation Degree to Risk Rank of Indicator in Smart Grid

\begin{tabular}{cccccc}
\hline indicator & $j=1$ & $j=2$ & $j=3$ & $j=4$ & $j=5$ \\
\hline $\mathrm{C}_{1}$ & -0.613 & -0.483 & -0.225 & 0.450 & -0.262 \\
$\mathrm{C}_{2}$ & -0.725 & -0.633 & -0.450 & 0.100 & -0.083 \\
$\mathrm{C}_{3}$ & -0.475 & -0.300 & 0.100 & -0.045 & -0.344 \\
$\mathrm{C}_{4}$ & -0.513 & -0.350 & -0.025 & 0.050 & -0.328 \\
$\mathrm{C}_{5}$ & -0.339 & -0.024 & 0.050 & -0.317 & -0.488 \\
$\mathrm{C}_{6}$ & -0.713 & -0.617 & -0.425 & 0.150 & -0.115 \\
$\mathrm{C}_{7}$ & -0.550 & -0.400 & -0.100 & 0.200 & -0.308 \\
$\mathrm{C}_{8}$ & -0.775 & -0.700 & -0.550 & -0.100 & 0.100 \\
$\mathrm{C}_{9}$ & -0.273 & 0.400 & -0.200 & -0.467 & -0.600 \\
$\mathrm{C}_{10}$ & -0.688 & -0.583 & -0.375 & 0.250 & -0.167 \\
$\mathrm{C}_{11}$ & -0.450 & -0.267 & 0.200 & -0.083 & -0.353 \\
$\mathrm{C}_{12}$ & -0.050 & -0.048 & -0.512 & -0.672 & -0.753 \\
$\mathrm{C}_{13}$ & -0.357 & -0.100 & 0.250 & -0.250 & -0.438 \\
$\mathrm{C}_{14}$ & -0.222 & 0.400 & -0.300 & -0.533 & -0.650 \\
$\mathrm{C}_{15}$ & -0.738 & -0.650 & -0.475 & 0.050 & -0.045 \\
$\mathrm{C}_{16}$ & -0.292 & 0.300 & -0.150 & -0.433 & -0.575 \\
$\mathrm{C}_{17}$ & -0.713 & -0.617 & -0.425 & 0.150 & -0.115 \\
$\mathrm{C}_{18}$ & -0.838 & -0.783 & -0.675 & -0.350 & 0.350 \\
\hline & - & & & & \\
\hline
\end{tabular}

Table 4. Risk Rank of Each Indicator

\begin{tabular}{lc}
\hline Risk rank & Assessment indicator \\
\hline $\operatorname{Higher}\left(R_{5}\right)$ & $\mathrm{C}_{8}, \mathrm{C}_{18}$ \\
$\operatorname{High}\left(R_{4}\right)$ & $\mathrm{C}_{1}, \mathrm{C}_{2}, \mathrm{C}_{4}, \mathrm{C}_{6}, \mathrm{C}_{7}, \mathrm{C}_{10}, \mathrm{C}_{15}, \mathrm{C}_{17}$ \\
$\operatorname{General}\left(R_{3}\right)$ & $\mathrm{C}_{3}, \mathrm{C}_{5}, \mathrm{C}_{11}, \mathrm{C}_{13}$ \\
Low $\left(R_{2}\right)$ & $\mathrm{C}_{9}, \mathrm{C}_{14}, \mathrm{C}_{16}$ \\
Lower $\left(R_{1}\right)$ & $\mathrm{C}_{12}$ \\
\hline
\end{tabular}

Correlation degree to risk rank of indicator in smart grid has been calculated according to Formula 8 and the result is here below.

$$
\begin{gathered}
K_{j}\left(p_{0}\right)=(-0.617,-0.479,-0.335,0.092,-0.203) \\
K_{j}=\max \left\{K_{j}\left(p_{0}\right)\right\}=0.092, j=4
\end{gathered}
$$


The above result shows that the combined risk of current smart grid is high $R_{4}$ ( $j=4$ ), especially in aspects of safety (The risk rank of $\mathrm{C}_{15}, \mathrm{C}_{17}$, and $\mathrm{C}_{18}$ are $R_{4}$ or beyond) and technology (The risk rank of $\mathrm{C}_{1}, \mathrm{C}_{2}$, and $\mathrm{C}_{4}$ are $R_{4}$ or beyond).

\section{Conclusions}

In this paper, we analyzed risk influence factors in smart grid, and then built a risk assessment indicator system based on matter-element Extenics. Finally, we comprehensively analyzed and rated risks in smart grid to conclude that the combined risk of smart grid in China is still high. Therefore, we should continuously research smart grid technology and risk prevention measures while developing the smart grid to make it robust, to ensure its operation safe and to low its risk.

\section{Acknowledgment}

This paper is supported by the Fundamental Research Funds for the Central Universities (Grant No.2015MS36) and the State Grid Corporation headquarters projects (Grant No.KJGW2015-020).

\section{References}

[1] Z. Ming, C. Yingjie, H. Xianzhong and D. Dapeng, "The Risk Assessment of China's Smart Grid Based on Multi-Level Fuzzy Comprehensive Evaluation Method [J]", East China Electric Power, vol. 39, no. 4, (2011), pp. 535-539.

[2] S. Qiang, GE Xubo and L. Lin, "Review of Smart Grid Comprehensive Assessment Systems [J]", Proceedings of the CSU-EPSA, vol. 23, no. 6, (2011), pp. 105-110.

[3] Z. Ming and W. Lei, "Risk Assessment of Smart Grid Based on Rating Correlation Analysis and Gray Triangle Clustering [J]", East China Electric Power, vol. 41, no. 2, (2013), pp. 245-248.

[4] C. Wenjun, "Research on Market Risk Transmission Model in Distributed Generation Oriented Smart Grid [D]", Beijing: North China Electric Power University, (2013).

[5] R. Yaqin, "Smart Grid Project Risk Assessment Model and Applied Research[D]", Beijing: North China Electric Power University, (2014).

[6] "Research on Smart Grid Operational Management Risk Element Transmission Model and Decision Support System [D]", Beijing: North China Electric Power University, (2014).

[7] C. Wen, "Matter-Element Model and Its Application[M]", Beijing: Scientific and Technical Documentation Press, (1994).

[8] C. Wen, Y. Chunyan and HE Bin, "New Development of the Basic Theory of Extenics [J]", Engineering Science, vol. 5, no.2, (2003), pp. 80-87.

[9] S. Sheng-yuan, W. Qing, S. Tao and B. Shou-chao, "Extenics Assessment of Engineering Geological Zoning of Foundation Soil in Tianjin Binhai New Area[J]", Journal of Northeastern University (Natural Science), vol. 35, no. 10, (2014), pp. 1502-1506.

[10] Y. Yang, "Research on Credit Evaluation of Commercial Bank Customer Based on the Theory of Risk Element Transmission[D]", Beijing: North China Electric Power University, (2013).

[11] HE Yongxiu, "Electric Power Comprehensive Assessment Method and Application[M]", Beijing: China Electric Power Press, (2011).

[12] X. Yafu and Z. Xiaokang, "B2B Customer Value Evaluation System Based TOPSIS with the Integrated Weight by AHP and Entropy[J]", Review of Computer Engineering Studies, vol. 3, no. 1, (2016), pp. 16-23. 


\section{Authors}

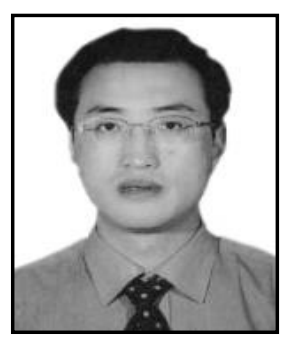

Jing Zhou, He received a master degree in Computer Application Technology from North China Electric Power University, Beijing, China, in 2005. He is currently working for PHD degree in the School of Economics and Management, North China Electric Power University, Beijing, China. His current research interests include different aspects of Data Mining and Decision Support System.

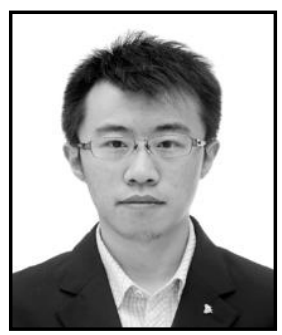

Zhaoxi Mu, He holds a bachelor's degree, and is now majoring in electrical engineering and automation for his master degree in North China Electric Power University. So far, one of his research interests is power grid emergency scheduling. 